Research Article

\title{
Exploring the Role of the Student Affairs Office in Enhancing the Cultural and Social Experiences of International Students in China
}

Robert Lucas Kaniki \& Hilda Lukas Kaniki ${ }^{\mathrm{ii}}$

\begin{abstract}
Many universities are hosting and enrolling international students as an important aspect of their internationalisation mission of higher education. However, many international students experienced significant problems adjusting into a host culture and social milieu. Informing this qualitative study were 45 international students in a top-tier comprehensive research university in Southeast China. The study focuses on the experience of international students towards the role played by international Fu Da Yuans (Counsellors) in enhancing the students' cultural and social experiences at the university. The results indicate that the four most significant adjustment issues for international students are the language challenges, social interaction with Chinese students, cultural orientation programmes, and counselling services for international students. Building on the U-Curve adjustment theory (Oberg, 1960), the study revealed the importance of international Fu Da Yuans to provide cultural and social support to international students for easy adjustment into a new culture and social setting. The study bears practical implications to providing international Fu Da Yuans with important insights that can help to create an environment conducive to enhancing the cultural and social experiences of international students.
\end{abstract}

\section{Keywords}

Cultural experience, social experiences, Fu Dao Yuan, student affairs, international students

i Robert Lucas Kaniki, Xiamen University, China, kanikirobert@yahoo.com

ii Hilda Lukas Kaniki, Beijing Normal University, China 


\section{Introduction: Background to International Students in China}

Chinese Universities have recently experienced an increase in international students' enrollment from different parts of the world. During the establishment of the People's Republic of China from 1949 to the 1980s, only 50,000 foreign students studied in China, and most of them pursued short-term language studies. However, due to reform and the opening-up Policy in 1978, China has experienced a rapid process of transformation of its political, economic, educational, and social systems. The implementation of new policies and reforms in higher education has emphasised the international mobility of students, which opened the doors for many international students to study in China. The aim was to stress the importance of international educational collaboration, and advancing internationalisation to enhance the nation's global position, to influence competitiveness in the field of education, and to transform from a country categorised as being a source of international students, to a destination for many international students (Huang, 2016; Ying, Kamnuansilpa \& Hirofumi, 2018; Kuroda, 2014).

By 2003, the Chinese government started various actions to attract foreign students to China. In 2003 alone, the number of international students in China reached 77715 from 175 countries (Huang, 2007). Currently, the government of China, through the Ministry of Education (MOE) and other governmental institutions, offers scholarships to international students for both short-term and long-term studies at all levels (CSC, 2019). The expansion of governmental support for international student enrollment has influenced many universities in China to introduce an international education curriculum, which offers several bachelor and graduate programmes to foreign students; programmes that have attracted many foreign students to join Chinese universities. The latest statistics from China's Ministry of Education highlight the strong growth in China's foreign enrollment. In 2017, a total of 489200 international students enrolled in Chinese Institutions, an increase of $10.5 \%$ from 2015. Another important step toward the country's long-term goal is to host 500000 students by 2020 (ICEF Monitor, 2018; MOE, 2018; Li, 2015).

\section{Overview of the Literature on Student Affairs in Chinese Universities}

In Chinese universities there is a unique student affairs position, called "Fu Dao Yuan," which can be translated as the "counsellor". The system of having Fu Dao Yuans in Chinese universities was introduced in 1952 (Li \& Fang, 2017; Lin \& Peng, 2003). Fu Dao Yuans in China originally had nothing to do with student affairs; instead, they were supposed to provide ideological and political education to the students (Zoe, 2017). With the development of higher education in China, the duties of $\mathrm{Fu}$ Dao Yuans were reviewed by the revolutionary committee of Tsinghua University during the great cultural revolution in 1976, and was believed to be politically incorrect (Li \& Fang, 2017; Lin \& Peng, 2003). In 1978, after several reforms, the new system of 
Chinese student affairs was applied in all Chinese universities, and the duties of Fu Dao Yuans (counsellors) gradually expanded to include consulting, moral education, cultural exchange, career advising, mental health, financial aid, student integration, recreation, day-to-day living, leadership, and so on (Li \& Fang, 2017; Zoe, 2017).

In order to ensure professionalisation of student affairs and all matters concerning student's services within Chinese universities are well-considered, the Ministry of Education published the standards for core competencies of Fu Dao Yuans. According to the document, Fu Dao Yuans should have a bachelor's degree and above, with no limitation on the major (Zoe, 2017). Although many Fu Dao Yuans initially study a major called "ideological and political education", this major emphasises theories instead of practice to the occupation of student affairs administration. To get more practical skills, many Fu Dao Yuans are studying for a certificate of psychological consultants and career development mentors (Li \& Fang, 2017; Lin \& Peng, 2003; Zoe, 2017).

\section{Approaches to International Student Services}

Despite many transformations to the higher education system in China since the 1990s, many ideas of a centralised planned system, inspired by the Russian system in the early 1950s, still exists in contemporary Chinese university systems, for example, Chinese universities have a centralised model of administration where all international students are admitted into a single faculty of international education. Although international students take courses in different faculties of their academic specialisation, all their services are provided by staff at the faculty of international education (Liu \& Lin, 2016).

Chinese universities have adopted a vertical network system to provide services to students called the "parental or nanny" approach to service provision (Liu \& Lin, 2016). Upon admission of international students in every department, there is a $\mathrm{Fu}$ Dao Yuan for international students, who are in charge and responsible for a full spectrum of issues concerning international students. The international Fu Dao Yuan is a single stop shop of services for all international students; international students do not need to worry about students' visa applications, medical insurance purchases, contact with the migration office, moral education in their day-to-day living, and connecting with the hospitals in case of any emergency. International Fu Da Yuans also make sure international students are registered for the right courses, meet all requirements for graduation, and are comfortable living in student residences (Liu \& Lin, 2016). If necessary, student financial aid office should also send the financial-aid policies to the international Fu Da Yuans, and the international Fu Da Yuans will help the needy students to apply. In addition, the cell phones of international Fu Dao Yuans are supposed to be available 24/7 for students under their care (Liu \& Lin, 2016; Zoe, 2017). This is the reason why it is called a vertical network system or parental/ nanny approach to student services. 


\section{Cultural and Social Problems Encountered by International Students}

Once international students encounter a problem or have any issue, they will report to the international Fu Dao Yuan of the department. If this issue was beyond the capacity of the international Fu DaoYuan to resolve, the international Fu DaoYuan had to report to the faculty administrator in charge of student affairs, and if the faculty administrator could not resolve the problem within the faculty, it was channelled to the Dean of students at an institutional level (Li \& Fang, 2017; Lin \& Peng, 2003). The duties of international Fu Dao Yuans include everything about international student life. It is a complicated duty because it is impossible for a single person to solve all the problems alone (Zoe, 2017). International Fu Dao Yuans only get assistance from faculty administrators or Deans of students at the institutional level when the issue is very serious. So, the system places much pressure on the shoulders of international $\mathrm{Fu}$ Dao Yuans, and it is challenging to distinguish serious cases from trivial ones (Liu \& Lin, 2016; Zoe, 2017).

In spite of using the parental/nanny approach to provide services to international students in Chinese universities, research on international students in China reveal that although international students have high educational aspirations and positive attitudes toward their education, they still experienced significant problems in adjusting to the host culture and social milieu (Dervin et al, 2018; Li, 2015; Yang, 2018). The cultural difference, language barriers, lack of social interaction with host students, food incompatibilities, internet restrictions, and lack of counselling services for international students were widely recognised in many works of literature as the major problems for international students in China (Chen, 1999; Gaw, 2000; Wen, 2005; Yost \& Lucas, 2002). Wen (2005) and Yost and Lucas (2002) noted that inadequate cultural experience and lack of social support mechanisms of international students created obstacles in social integration with host people. These obstacles led to international students starting to experience situations of uneasiness that were detrimental to their individual psychology, such as feelings of isolation, loneliness, and frustration (Yang, 2018; Zhai, 2002). These problems could be seen as culture shock: "a psychological disorientation experienced by people who suddenly enter radically different cultural environments to live or work" (Oberg, 1960). The roles and endeavours of international Fu Dao Yuans are inevitable to enhance the culture and social experiences of international students in China.

\section{Theoretical Approach}

The theoretical background of this paper hinges on the Oberg (1960) U-Curve adjustment theory (UCT). Specifically, it portrays the transition and adaptation process from old culture to new culture, as well as the social life. According to the UCT model, the transition and adaptation process goes through four stages. The honeymoon stage occurs during the first to third weeks 
after arrival at the host country; individuals are fascinated by the new environment and different cultures. The initial cultural obsession is followed by the second stage of disillusionment and frustration, which is the culture shock stage. The newcomer starts to encounter frustration and irritation towards the host country and people after experiencing the culture on a daily basis. The third stage is the adjustment stage, in which the individual gradually adapts to the new norms and values of the host country after being exposed to cultural and social support mechanisms. At this stage, individuals can act more appropriately than before. Finally, the mastery stage is characterised by an additional increase in the individual's ability to function effectively in the new culture and social settings (Figure 1) (Black \& Mendenha, 1990; Lysgaard, 1955; Oberg, 1960). As it was suggested in the third stage of U-Curve adjustment theory (Oberg, 1960), the model was appropriate for exploring how the international Fu Dao Yuans played an important role in enhancing the cultural and social experiences of international students in China.

\section{Degree of Adjustment}

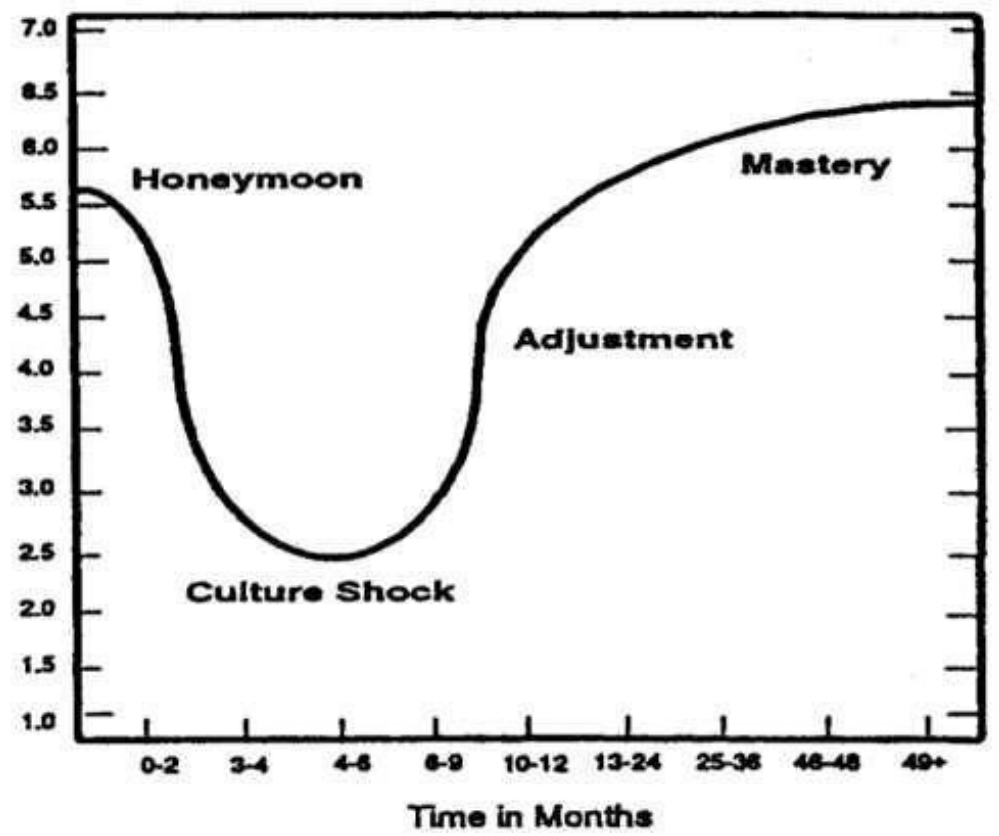

Figure 1. The U-Curve adjustment pattern (Adapted from Oberg, 1960)

\section{Methods}

The study employed a qualitative design, as it was an empirical study that aimed to reveal the experiences of international students in China beyond those that might already have 
been predicted. To achieve the research aim, in-depth focus group interviews were employed as a relevant approach in accessing different categories of information, such as motivations, thoughts, and understandings of participants (Coles \&Swami, 2012).

\section{Research Design}

The research design selected for the study was an embedded single-case approach (Yin, 2018), thus being helpful for showing a multifaceted picture of cultural and social experiences of international students in a chosen university. One top-tier comprehensive research university in Southeast China was selected as a site for the study because it promoted internalisation. The institutional site was a public university, ranked in the top twenty of over 2000 Chinese universities. The institution had a total enrolment of approximately 40000 students, including 3500 international students from over 130 countries and regions (University Prospectus, 2019).

\section{Participants}

A convenient sample of 45 male and female international students participated in the study. The participation was voluntary, such that the students were willing and enthusiastic to share their insights about cultural and social experiences. Table 1 below describes characteristics of the participants.

Table1. Characteristics of participants

\begin{tabular}{|c|c|c|c|c|}
\hline $\begin{array}{c}\text { Country of } \\
\text { Origin }\end{array}$ & $\begin{array}{l}\text { Number of } \\
\text { Participants }\end{array}$ & Age Range & Gender & $\begin{array}{l}\text { Length of Stay } \\
\text { in China }\end{array}$ \\
\hline Indonesia & 3 & $24-28$ & $\begin{array}{l}\text { 2: Male } \\
\text { 1: Female }\end{array}$ & 1-2 Years \\
\hline Russia & 3 & $26-31$ & 3: Male & 1-3 Years \\
\hline Bangladesh & 3 & $26-30$ & $\begin{array}{l}\text { 2: Male } \\
\text { 1: Female }\end{array}$ & 2-3 Years \\
\hline USA & 2 & $24-28$ & 2: Male & 1-2 Years \\
\hline Zimbabwe & 2 & $26-30$ & $\begin{array}{l}\text { 1: Male } \\
\text { 1: Female }\end{array}$ & 1-3 Years \\
\hline Pakistan & 4 & $27-32$ & $\begin{array}{l}\text { 3: Male } \\
\text { 1: Female }\end{array}$ & 2-4 Years \\
\hline Tanzania & 1 & $26-30$ & 1: Male & 1 year \\
\hline
\end{tabular}




\begin{tabular}{|l|l|l|l|l|}
\hline \multicolumn{1}{|c|}{$\begin{array}{c}\text { Country of } \\
\text { Origin }\end{array}$} & $\begin{array}{c}\text { Number of } \\
\text { Participants }\end{array}$ & Age Range & \multicolumn{1}{|c|}{ Gender } & \multicolumn{1}{c|}{$\begin{array}{c}\text { Length of Stay } \\
\text { in China }\end{array}$} \\
\hline UK & 3 & $24-30$ & $\begin{array}{l}\text { 1: Male } \\
\text { 2: Female }\end{array}$ & 1-2 Years \\
\hline South Africa & 3 & $26-31$ & 3: Female & 2-3 Years \\
\hline Rwanda & 4 & $26-32$ & $\begin{array}{l}\text { 3: Male } \\
\text { 1: Female }\end{array}$ & 1-2 Years \\
\hline Philippines & 3 & $24-30$ & $\begin{array}{l}\text { 1: Male } \\
\text { 2: Female } \\
\text { 2: Male } \\
\text { 2: Female }\end{array}$ & 1-2 Years \\
\hline Ghana & 4 & $27-32$ & $\begin{array}{l}\text { 1: Male } \\
\text { 1: Female } \\
\text { 2: Male } \\
\text { 1: Female }\end{array}$ & 1-2 Years \\
\hline France & 2 & $24-28$ & 3: Male & 1-3 Years \\
\hline Nigeria & 3 & $26-30$ & 2: Male & 1-2 Years \\
\hline Liberia & 3 & $26-30$ & & \\
\hline India & 2 & & & \\
\hline
\end{tabular}

\section{Data Collection and Ethical Considerations}

To ensure the data collected attained the research aim, ethical considerations were significant in undertaking this study. The informed consent letter for participation was provided at the beginning of each focus group interview and all students were given enough time to read and understand it before the focus group discussions. Participants were allowed to withdraw at any time. The sample was 45 international students from 16 countries that were recruited for 9 focus groups, and each group contained no more than 5 participants.

\section{Data Analysis and Trustworthiness}

In spite of sharing their thoughts in a focus group, during data analysis, each participant was treated as a separate case. The pattern matching method was applied in an attempt to link an existing pattern that derived from theory, with the collected information (Alebeek \& Wilson, 2019; Trochim, 1989), and compared to the revealed description of cultural and social experiences of international students with $U$-curve adjustment theory. Cases were analysed from the coded transcriptions of each participant and later categorised into themes by adopting inductive coding (Thomas, 2003). This helped to condense wide and varied raw data through constant comparison into a brief format to form a single theme. The whole set of data was 
transcribed and coded by the interviewers (both authors). To ensure the trustworthiness of data, member checking (Lincoln \& Guba, 1985) was applied; the transcripts were sent back to the participants to prove that the respondents' experiences were represented as intended.

\section{Findings}

\section{Global contact zone and Nanny style of service provision}

In general, participants appreciated the opportunities and experiences of studying in China. The majority of participants described the university as a global educational contact zone. The students from around the world meet, interact, and learn from each other.

Chris, a student from Congo, noted that: "Coming to study in China has helped me to meet people from different parts of the World. China is like a mini globe...when you are in touch with people from other places, you learn a lot... The more you spend time with different people from different countries, the more you discover things and experience different cultures." Other international students commented on how the Nanny style of service provisioning was helpful in their daily life. The international Fu Dao Yuan as a single stop shop of services for international students took all responsibility for international student life, while students only need to passively receive services.

Zak, a student from France, noted that: "The style of service provision used by Fu Dao Yuans is very proactive...I was very happy when I realized Fu Dao Yuans are responsible for such issues assigned up for the right courses, visa application, arranging student's residences, purchase of medical insurance and so on...this kind of system simplifies my life here in the university."

However, some participants also think critically about the risks involved in the Nanny style of service provisioning, which could prevent the students from being proactive in finding out how various services in Chinese universities work, and how to access them on their own.

Kate, a student from Canada explained: "The style of service provision used by Fu Dao Yuans is very good, but I think to some extent it limits us to manage our own school and life issues as independent adults.... It makes us have little experience on how things work because things that can be handled by students themselves such as to make sure we sign up for the right courses, meet all requirements for graduations and so on, are done by international $\mathrm{Fu}$ Dao Yuans."

Echoing the findings of Liu and Lin (2016) and Zoe (2017), most often the duties of international $\mathrm{Fu}$ Dao Yuans are complicated because it is impossible for a single person to solve all the problems encountered by students. The system exerts considerable pressure on the shoulders of international Fu Dao Yuans and it is a real challenge to differentiate special issues from trivial ones. This trend was reflected by many participants who believed that the 
international $\mathrm{Fu}$ Dao Yuans, in charge of different departments, had a limited role in enhancing the cultural and social experience of international students because of its numerous duties. The system weaves all students and makes it difficult for international Fu Dao Yuans to focus on cultural and social programmes for international students. The findings revealed that the language challenges, social interaction with Chinese students, cultural orientation programmes, and counselling services for international students were the four most significant adjustment issues for international students.

Language challenges were the most often mentioned issue by respondents, as it limits the cultural and social experiences of international students. Participants revealed inadequate efforts taken by international Fu Dao Yuans to promote different programmes and activities in favour of language learning. Leonard from Nigeria illustrated: "Still there are limited efforts taken by international $\mathrm{Fu}$ Dao Yuans to create a conducive and alternative environment for us to master the language. For example, there is no active language exchange program to enable mutual learning with host students, where Chinese students could learn foreign languages and we could also learn Chinese language easily."

\section{Cultural orientation for international students}

Respondents reported that the international Fu DaoYuans had little focus on providing cultural orientation programmes to address cultural differences within the university. The orientation programmes were mainly focused on academics; for example, how to use the library, course selection, and other academic services. Most of the students usually consulted their fellow senior international students regarding their difficulties in adjusting to a new culture, although the senior students also had similar adjustment issues. Clara from the UK described how orientation programmes played a minor role in enhancing the culture and social experience of international students in the university: "Before I came to China, I had no idea how life could be in university, but I was expecting the orientation programs could easily help me to get familiar with the host culture and social life. But I think the orientation programs are not focused much on enhancing the cultural and social experiences of international students... They emphasize much on academic orientation."

\section{Social interaction with Chinese students}

The international students revealed that they felt very isolated from Chinese students and their culture. These kinds of experiences led to frustration, confusion, and emotional discomfort among the international students because they lack familiar signs and belonging. Responses show that there were few effective programmes to bridge international and Chinese students. For example, active extracurricular activities for international and Chinese students to help 
them easily get to know each other. Some students admitted to having been involved in some programmes designed by international Fu Dao Yuans to bring international and Chinese students together for the purpose of sharing their culture, but most of those programmes lacked effectiveness and were not efficient Shab from India stated: "One time, I got information from $\mathrm{Fu}$ Dao Yuan of our department about the social program called the English-Chinese corner. In that program international and Chinese students could come together to learn the languages and cultures of each other by playing some interesting games while speaking both English and Chinese languages, also it could help students to make friends. Honestly, it was a nice program but it lacked effectiveness and seriousness which made many students lose interest in attending the program."

\section{Counselling services for international students}

Commenting on their experiences in the counselling programmes for international students with cultural differences, the majority of participants identified counselling as one of the most important factors in enhancing cultural and social experiences; therefore, designing counselling programmes to help international students who felt very isolated from Chinese students and culture, those who experience frustration, confusion, and emotional discomfort would help them easily adapt to the host culture and social settings. Angel from Ghana stated: "I really appreciate the services provided by international Fu Dao Yuans; they are really helpful. But they should also consider having counselling programs for international students just as what they have for Chinese students. It will easily facilitate adjustment into the new cultural and social life.

Other participants mentioned the lack of awareness of counselling services available for them. Abdul from Pakistan argued that: "Frankly speaking, I have no idea where I can seek professional counselling services in the University. The office which I frequently use is the office of international $\mathrm{Fu}$ Dao Yuan, for issues like course registration, visa application, and so on, but not for counselling services."

\section{Discussion}

This article examined the role played by the student affairs office in supporting international students to have successful cultural and social experiences based on their perceptions and experiences in China. Many studies about international students in China integrated the academic and cultural experience of international students. The study has differentiated them, considering how they are important in different ways. The U-Curve adjustment theory (Oberg, 1960) was employed particularly in its stage of adjustment, to examine the adjustment trajectory of international students in a new culture. The study discovered that 
the international Fu Dao Yuans in Chinese universities are central in the enhancement of cultural and social experiences of international students; because it confirmed that there was a connection between international $\mathrm{Fu}$ Dao Yuans and international students. The office of international Fu Dao Yuans was the most used office by international students who sought services such as visa applications, course registration, travelling, legal problems, purchasing of health insurance, comfortable living standards in student residences, and so on.

Providing cultural and social support to international students to successfully enhance their status is vital and deserves further attention in many Chinese universities. The cultural and social support should not only be for the positive well-being of international students, but also for helping them to cope with the host culture and society. By placing great emphasis on language and communication programmes, cultural orientation for international students, social interaction and counselling services for international students, will help the international students from diverse backgrounds to easily adjust to the host culture and society. With a completely enhanced status, the international students will not only accept the host country's customs but will also begin to enjoy its social life and studies.

\section{Practical Recommendations}

Given the recent increase of international students in Chinese higher education coming from diverse backgrounds, the process of cultivating international $\mathrm{Fu}$ Dao Yuans in Chinese universities should be combined with the increasing level of international students in China, to ensure enough international Fu Dao Yuans with manageable duties. This will help them to put more focus on cultural and social programmes for international students. The practical recommendations developed from international students' experiences are essential for international Fu Dao Yuans interested in enhancing the culture and social experiences of international students in China.

Firstly, the international Fu Dao Yuans must ensure that the orientation programmes for international students are not primarily focused on academic programmes, but should also focus on enhancing the cultural and social experiences of the international students. Enhancing cultural experiences in universities can be achieved by designing orientation programmes that promote easy adjustment of international students into the host culture. Huntley (1993) stated that a well-organised orientation can also help international students become aware of aspects of university life and then adjust better. Furthermore, Pedersen (1991) stated that: "orientation is a continuous process requiring contact with students before they arrive and during their stay", therefore, the study suggested that the educational and cultural information about host universities must be made more readily available to prospective international students before they leave their home countries, so that they can be prepared or at least be aware of the differences before leaving. 
Secondly, improving counselling services for international students; the study confirmed that many international students were not aware of counselling services that are available to them. Under these circumstances, it is important for international Fu Dao Yuans to create better connections with international students in terms of personal emotional issues, so that they can openly share their feelings and indicate if they need any help. Pedersen (1991) presented an alternative technique of providing counselling services to international students, which is beyond the formal counselling technique. He recommends a harmonising system of informal methods, for instance, going to where the students live or hanging out, whether at home, on campus benches, hallways, or street corners and taking part in social actions.

Thirdly, strengthening language support; many international students are still facing several difficulties in using the host language for communication. For instance, the study discovered that participants consider the Chinese language as the main challenge in coping with the host environment. International $\mathrm{Fu}$ Dao Yuans should go beyond the one-semester host language course and design continuing programmes such as mini communication workshops, which could help to reveal some commonly used words in the social and academic setting to international students. Furthermore, Robinson (1992) suggested making the implicit cultural knowledge explicit in their instruction. This is providing opportunities to develop essential knowledge of the host culture. Therefore, the integration of cultural and academic guidance while teaching is vital in enhancing international students' cultural competence.

Lastly, international $\mathrm{Fu}$ Dao Yuans should help to create interaction opportunities between host students and international students. Zhai (2002) argued that international students who spent more of their leisure time with host students are significantly better adapted than those who spent more leisure time with their fellow country mates. A variety of active and efficient programmes such as English-Chinese conversation programmes, culture clubs, and international festivals could be designed by international $\mathrm{Fu}$ Dao Yuans to enhance the cultural and social experiences of international students.

\section{Limitations and Further Research}

Practically, and within the constraints of research, the study recruited only international students in a single university to share their experiences. It is therefore suggested that future research could further investigate students' experiences and international $\mathrm{Fu}$ Dao Yuan activities in many Chinese universities. Participants' experiences might differ from those of students in other well-developed institutions, which are considered world-class universities. The study encourages future research by using various methods such as quantitative or mixed-methods research, which could provide a better understanding and richer data on the cultural and social experiences of international students in China. 


\section{References}

Alebeek, W., \& Wilson, K. (2019). Explaining the college choice decisions of international students at a regional university in the United States. Journal of Research in International Education, 18(3), 292-309.

Black, S., \& Mendenhall, M. (1990). The U-Curve adjustment hypothesis revisited: A review and theoretical framework. Journal of International Business Studies, 44(3), 456-518.

Chen, P. (1999). Common stressors among international college students: Research and counselling implications. Journal of College Counselling, 34(2), 49-65.

China Scholarship Council (CSC). (2019). International Students in China. http:// en.csc.edu.cn/Laihua/indexen.aspx

Coles, R., \& Swami, V. (2012). The sociocultural adjustment trajectory of international university students and the role of university structures: A qualitative investigation. Journal of Research in International Education, 11(1), 87-100

Dervin, F., Härkönen, A., \& Du, X. (2018). International students in China:A dream come true. In: Dervin F, Du X and Härkönen A (eds) International students in China: education, student life and intercultural encounters. Palgrave Macmillan imprint, 14(8), 335-369.

Gaw, F. (2000). Reverse culture shock in students returning from overseas. International Journal of Intercultural Relations, 24(1), 83-104.

Huang, F. (2016). International mobility of students, academics, educational programs, and campuses in Asia. Education in the Asia-Pacific Region, 104(4), 315-467.

Huang, F. (2007). Internationalization of higher education in the era of globalization: What have been its Implications in China and Japan? Journal of Higher Education Management and Policy, 78(3), 47-60.

Huntley, S. (1993). Adult international students: Problems of adjustment. Eric Document Reproduction Service, 25(6), 338-349.

International Consultants for Education and Fairs [ICEF] Monitor. (2018). Foreign enrolment in China. http://monitor.icef.com/2018/05/foreignenrolment- china-10-5-2017/

Kuroda, C. (2014). The new sphere of international student education in Chinese higher education: A focus on English-medium degree programs. Journal of Studies in International Education, 18(5), 445-462.

Li, X. (2015). International students in China: Cross-cultural interaction, integration, and identity construction. Journal of Language, Identity, and Education, 14(4), 237-254.

Lin, T., \& Peng, Q. (2003). The features and developments of "Fu Dao Yuan" system at Tsinghua University. Tsinghua University Journal of Philosophy and Social Science, 51(6), 13-17.

Lincoln, S., \& Guba, G. (1985). Naturalistic inquiry. Sage.

Liu, W., \& Lin, X. (2016). Meeting the needs of Chinese international students: Is there anything we can learn from their home system? Journal of Studies in International Education, 
20(4), 357-370.

Li, Y., \& Fang, Y. (2017). Professionalization of student affairs educators in China: History, challenges, and solutions. Journal of Student Affairs in Africa, 5(1): 41-50.

Lysgaard, S. (1955). Adjustment in a foreign society: Norwegian Fulbright grantees visiting the United States. International Social Science Bulletin, 128(7), 45-51.

Ministry of Education (MOE). People's Republic of China (2018). Statistics of international students in China. http://www.moe.gov.cn/publicfiles/ usiness/htmlfiles/moe s5987/201202/1311 17.html

Oberg, K. (1960). Cultural shock: Adjustment to new cultural environments. Practical Anthropology 67(7), 177-182.

Pedersen, B. (1991). Counselling international students: The counselling psychologist. http:// www.fuberlin.de/gerund/Public/world_data.htm

Robinson, J. (1992). International students and American university culture: Adjustment issues. www.mindoh.com/docs/Confidence_ estsBummer.pdf

Thomas, D. (2003). A general inductive approach for qualitative data analysis. American Journal of Evaluation, 27(2), 237-246.

Trochim, K. (1989). Outcome pattern-matching and program theory. Evaluation and Program Planning, 12(4), 355-366.

University Prospectus for International Students. (2019). Xiamen University. http://admissions. xmu.edu.cn

Wen, L. (2005). Perceptive of expatriation and cross-cultural adjustment. National Chiayi University, 25(4), 103-118.

Ying, L., Kamnuansilpa, P., \& Hirofumi, A. (2018). Factors affecting international students' decisions on destination for studying abroad: A Case Study in China. Journal of Higher Education, 13(1), 93-118.

Yost, D., \& Lucas, S. (2002). Adjustment issues affecting employment for immigrants from the former Soviet Union. Journal of Employment Counselling, 39(4), 456.

Yin, K. (2018). Case study research and application: Design and Method. SAGE Publication Inc, 56(2), 543-562.

Zhai, L. (2002). Studying International Students:Adjustment Issues and Social Support. Research and Planning, 4(12), 34-78.

Zoe, T. (2017). Nature \& origin of student affairs in China. NASPA. https://www.naspa.org/ blog/a-brief-intro-to-student-affairs-in-china 